\title{
Editorial da Edição Especial do Laboratório de Planejamento e Monitoramento Ambiental LPMA/UFSM
}

\author{
Pedro Daniel da Cunha Kemerich \\ Professor da Universidade Federal de Santa Maria - UFSM/CESNORS \\ e-mail: eng.kemerich@yahoo.com.br \\ Willian Fernando de Borba \\ Acadêmico do Curso de Engenharia Ambiental da Universidade Federal de Santa Maria, \\ Campus Frederico Westphalen - RS. \\ e-mail: borba_willian@hotmail.com
}

A edição especial Laboratório de Planejamento e Monitoramento Ambiental - LPMA/UFSM, traz alguns dos trabalhos desenvolvidos pela equipe de trabalho do LPMA/UFSM nos anos de 2009 à 2013. Temos neste período a comemoração dos três anos de criação do Laboratório e a grata felicidade da obtenção do conceito máximo (Conceito 5) pelo Curso de Engenharia Ambiental da Universidade Federal de Santa Maria - UFSM/CESNORS na avaliação do INEP/MEC.

Nesta edição estão sendo apresentados trabalhos frutos de Projetos de Pesquisa e Extensão coordenados pelos Professores Pedro Daniel da Cunha Kemerich, Alexandre Couto Rodrigues e Aline Custódio Ferrão Passini e também com pesquisadores parceiros nas mais diversas áreas, tais como: alterações nos parâmetros de qualidade da água em cursos de água, alterações nas propriedades do solo sob derramamento de lixiviado de aterro sanitário, tratamento de esgoto sanitário com plantas, concentrações de metais em solo ocupado por cemitério, gestão de resíduos sólidos em oficina mecânica e usina de triagem, viabilidade de implantação de sistema de esgotamento sanitário em Goiânia, compostagem como forma de tratamento de resíduos orgânicos de restaurante universitário, uso e ocupação do solo em bacia hidrográfica, fontes alternativas de abastecimento de água em Frederico Westphalen-RS, vulnerabilidade natural a contaminação e infiltração de água no solo na zona urbana de Frederico Westphalen

Assim, a equipe agradece ao periódico a oportunidade disponibilizada. 